\title{
Public health economics of vaccines in the Netherlands: methodological issues and applications
}

\author{
Maarten J. Postma
}

Received: 4 March 2008 /Accepted: 29 April 2008 /Published online: 25 June 2008

(C) The Author(s) 2008

\begin{abstract}
Aim This article seeks to highlight the methodological issues involved in the public health economics of vaccines in the Netherlands and the ensuing implications for immunisation policy.

Subjects and methods We review and analyse the role of health economics (and especially cost-effectiveness issues) in the decision-making process of the Dutch (1) Drugs Reimbursement System and (2) National Immunisation Programme. Different types of health-economic analyses are illustrated by the examples of meningococcal $\mathrm{C}$, pneumococcal, and human papilloma virus (HPV) vaccines. Results The role of health economics has recently increased in importance in Dutch public health decision-making concerning vaccines. The choice of vaccine strategy against meningococcus $\mathrm{C}$, the shift in favour of introducing pneumococcal vaccine, and the prolonged decision on the reimbursement for HPV vaccine were all related to the health-economic component in the recommendation process. Conclusion The role of health economics is growing in decision-making regarding the reimbursement of new therapeutic and prophylactic products. Vaccines, like drugs, will have increasingly to prove their cost-effectiveness if manufacturers are to lead their product not only from phases I to IV, but also through to implementation as part of national immunisation policies covered within national reimbursement systems.
\end{abstract}

M. J. Postma ( $\varangle)$

Department of Pharmacy, University of Groningen,

Groningen, The Netherlands

e-mail: m.j.postma@rug.nl
Keywords Public health economics - Immunisation policy · Meningococcal C vaccine P Pneumococcal vaccine. Human papilloma vaccine

\section{Introduction}

The role of public health economics and in particular of cost-effectiveness analysis has been growing in decisionmaking regarding the reimbursement of new vaccines in many countries, including the Netherlands. To the three traditional hurdles of leading a new vaccine all the way to licensing (quality analysis and manufacturing, efficacy in clinical trials, and toxicity and safety assessments) has been added a fourth, increasingly important one: health-economic analysis. In the Netherlands, we have recently seen the importance of the fourth hurdle both for vaccines within the National Immunisation Programme (NIP) and for manufacturers striving to have their vaccine reimbursed within the Drugs Reimbursement System ("Geneesmiddel Vergoedings Systeem", GVS). Respective examples, also to be discussed below, are the pneumococcal and HPV vaccines.

In this paper, we will illustrate the role of healtheconomics analysis in the Netherlands when taking public health decisions on vaccination policy, where vaccines recently introduced on the market and/or recently re-visited due to changing epidemiological situations are concerned. In particular, vaccines against meningococcus, pneumococcus, hepatitis B virus (HBV), rotavirus (RV), and human papilloma virus (HPV) have been prominent in Dutch policy making over the past 5 years. In all cases, specific health-economic features concerned both the exact methodology applied to estimate cost-effectiveness and the recommendation/decision provided. The analysis presented below is specific to the Netherlands, but may serve as a 
useful example for many Western European and North American countries with regard to the health-economic assessment.

\section{The Dutch Drugs Reimbursement System}

The Dutch Drugs Reimbursement System has included health-economic analysis as a further criterion for access as of 1 January 2005 (Rutten 2004). Since that time, newly registered drugs and vaccines must be able to prove their cost-effectiveness in addition to their clinical added value. The system for access to the Drugs Reimbursement System was clearly initially designed for outpatient drugs rather than vaccines. Until quite recently, economic analyses for reimbursement issues have concerned typical outpatient drugs such as clopidogrel (prevention of arterial disorders), long-acting risperidone (anti-psychotic drug), oseltamivir (oral anti-viral drug), long-acting drugs for Attention Deficiency Hyperactivity Disorder, etc. (Postma et al. 2007b; Heeg et al. 2005, 2007). In all, nearly 30 drugs now have an economic file included in the reimbursement process. It is worth noting that reimbursement of such drugs by the Drugs Reimbursement System is not a straightforward or simple process, and various manufacturers have failed to achieve reimbursement for their outpatient drugs.

Designed for the "classical" outpatient drug, the Drugs Reimbursement System has recently received requests from vaccine manufacturers to include vaccines on one of the reimbursement lists (1A, 1B, and list 2, being for clusters of equivalent drugs, unique drugs with added value, and additional conditions for reimbursement, respectively). In particular, these requests concerned vaccines that are not (yet) part of the NIP, i.e. HPV and RV vaccines.

Neither of the two has yet obtained reimbursement status nor a positive recommendation for reimbursement within the Drugs Reimbursement System, which shows just how arduous it is for a drug/vaccine to be registered on one of the Drugs Reimbursement System's lists (www.cvz.nl, accessed January 20th 2008). In neighbouring countries, for example, Belgium, positive recommendations for both vaccines and first arrangements for reimbursements have existed since 2007 (www.kce.be, accessed 25 April 2008).

Clinical, epidemiological, and also health-economic considerations all play a role in the reimbursement process. The whole process is a complex superimposition of advisory boards composed of specialists and academics: Committee Pharmaceutical Help (Commissie Farmaceutische Hulp, Utrecht), the Foundation for Health Care Insurance (College voor Zorgverzekeringen CvZ, Diemen), and the Ministry of Public Health, Welfare \& Sports $(\mathrm{MoH})$. It is the $\mathrm{MoH}$ that has the last say on reimbursement.

Advisory boards tend to advise along the same lines; however, this does not always occur, and examples exist where the advice has differed from one board to the other. The classic example in the Netherlands is Viagra ${ }^{\circledR}$, for which each successive advisory board limited further the target group for reimbursement such as in the end the $\mathrm{MoH}$ decided not to reimburse the drug at all (Heeg et al. 2007; www.cvz.nl, accessed 20 January 2008).

\section{National Immunisation Programme (NIP)}

Since the turn of the century a separate committee of the Health Council advises the $\mathrm{MoH}$ on the state-of-the-art of scientific aspects concerning those vaccines within the Dutch NIP and new vaccines to be considered for the Programme (www.gr.nl, accessed January 20th 2008). Within this committee, health economics play a role next to clinical, epidemiological, ethical, and practical aspects. On the one hand, the committee provides basic advice: for example, general criteria for a vaccine to be eligible for the NIP as a function of disease burden, public health nature of the infection, and equity. On the other hand, the committee delivers targeted and timely advice on specific vaccines under discussion regarding inclusion, exclusion, or substitution in the programme.

To cite a few examples, general recommendations have been issued and specific reports produced on meningococcus, pneumococcus, pertussis, and HBV vaccines (Health Council 2002, 2004, 2005, 2007). Related committees have recently produced reports (or are in the process of doing so) on influenza vaccination for the elderly and the HPV vaccines Cervarix ${ }^{\circledR}$ and Gardasil ${ }^{\circledR}$. Public health-economic arguments are always largely accounted for when issuing such recommendations (Postma et al. 2007a).

Vaccine manufacturers may prefer to have their vaccine included in the NIP, given the large potential market. However, decision-making concerning the introduction of new vaccines in the NIP appears to be relatively slow in the Netherlands. For instance, recent developments in HPV vaccination indicate that many countries have already achieved reimbursement within national programmes and have thus started vaccinating as of 1 January 2008 (Thiry et al. 2007), whereas the Dutch are still awaiting decisions concerning HPV and the NIP (situation April 1st 2008).

The route to reimbursement through the Drugs Reimbursement System is potentially quicker than that through the NIP, tempting manufacturers to present their vaccines preferably to the former institution. As far as the Drugs Reimbursement System is concerned, the manufacturer is in a "leading" position since according to the rules and regulations a full file has to be taken into consideration and the advisory process on the reimbursement has to be started up. Furthermore, a decision on reimbursement must be taken within a limited number of months after the manufacturer has presented the full reimbursement file to 
the Foundation for Health Care Insurance, including a health-economic assessment possibly performed or assigned by the manufacturers themselves.

In the process of seeking reimbursement through the NIP, on the other hand, the manufacturer is certainly not in a leading position, as there exist no legal limitations for the timeframe on issuing of recommendations by the Health Council.

Another potential delay in the Health Council recommendations process is the request for an independent health-economics assessment, i.e., one not performed by the manufacturer or within an assignment by the manufacturer. However, the manufacturer may be invited for hearings and scientific presentations that can speed up the process.

\section{Method}

Types of health-economic analysis

For reimbursement issues, three types of health-economics analysis are generally distinguished. Table 1 lists these analyses and some of their characteristic features. Basically, all types include the costs of the intervention (in this case: vaccination) and the related monetary savings. Costs of the intervention should include the initial investment costs of, for example, infant vaccination, but also possible follow-up costs, such as providing a booster vaccination to enhance long-term protection of immunisation. Savings relate to averted direct health-care costs, but may also relate to averted indirect non-health-care costs of production losses (also, vaccination costs may include indirect costs if work loss is connected to being vaccinated, with influenza vaccination for healthy working adults as one example) (Postma et al. 2005). It should likewise be noted that direct non-health-care costs and savings are included in economic analyses, reflecting for example travel costs to the healthcare sites. Costs and savings are subtracted from each other to define net costs.

Major differences between the three methods as listed in Table 1 relate to the health outcomes considered. In costminimisation analysis, health outcomes are generally not considered, and the framework is usually used for such situations only when safety and effectiveness of two drugs/ vaccines are considered equivalent. This type of analysis is generally insufficient for analysing new vaccines since they mostly quite obviously have something extra to offer (for instance HPV, RV, or acellular pertussis vaccines). Costeffectiveness analysis typically includes clinical outcomes averted relating to serious morbidity and/or mortality, e.g., complications and deaths averted, end-stage serious disease delayed, and-directly related to the latter-life-years gained. Cost-utility analysis includes quality of life as a major outcome, next to life-years gained. The typical outcome in which both life-years gained and quality impacts are integrated is the Quality-Adjusted Life-Year (QALY) (Postma 2003).

\section{Guidelines}

For the adequate conduct of such health-economics analyses, guidelines for good health-economics practice have been developed (www.ispor.com, accessed January 20th 2008). The number and exact nature of such guidelines differ according to country, but generally guidelines encompass "rules" for (1) how to conduct and interpret an incremental analysis, (2) how appropriately to discount money and health effects, and (3) how to design a model that incorporates all effects on financial and health outcomes during the appropriate time horizon (Foundation for Health Care Insurance 2004).

The guidelines are directly derived from the procedure for outpatient drugs that has existed in the Netherlands since 1 January 2005. In particular, it is stated there that a new drug should be compared in the incremental healtheconomic analysis with the best available alternative. Also, the exact discount rates to be used are specified at $4 \%$ for costs and $1.5 \%$ for health effects.

By way of example and with regard to the last "rule", it is often stated that dynamic models should be applied to vaccines in order to include secondary impacts on nonvaccinated as well as primary impacts on vaccinated groups. As vaccination generally reduces the spread of an infectious disease, vaccinating target groups (often infants) theoretically and practically limits the probability that nonvaccinated groups become infected, hence the expression that vaccination provides "herd immunity" to unvaccinated

Table 1 Types of health-economic analysis

\begin{tabular}{llll}
\hline Technique & Monetary aspects included & Clinical aspects included & Utility aspects included \\
\hline Cost-minimisation analysis & Costs and savings & Not applicable & Not applicable \\
Cost-effectiveness analysis & Costs and savings & Clinical outcomes and life years & Not applicable \\
Cost-utility analysis & Costs and savings & Life years & Quality of life \\
\hline
\end{tabular}

Source: Postma 2003 
groups. One example is the protection of the elderly against invasive pneumococcal disease as a consequence of infant vaccination programmes (Whitney et al. 2003; Lexau et al. 2005).

\section{Objective}

The objective of this paper is to review the role of healtheconomic analysis in some of the recent examples in Dutch decision making on reimbursing new vaccines in either the Drugs Reimbursement System or NIP, with special reference to the type of economic analysis and the guidelines.

\section{Results}

\section{Meningococcal $\mathrm{C}$ vaccine}

Dutch decision-makers were provided with cost-effectiveness information on introducing meningococcal serogroup $\mathrm{C}$ conjugate vaccination (NeisVac and Meningitec) in 20012002, resulting in the introduction of a programme in 2002 directed at 14-month-old infants (Welte et al. 2004). The analyses were published in Vaccine and typically followed a rigid incremental approach (Welte et al. 2004). An incremental approach was required as various scenarios for vaccinating could be considered. In particular, (1) oneoff vaccination at 14 months, (2) two doses at 5 and 6 months, and (3) three doses very early in infancy (2, 3 and 4 months) were all assumed to provide similar longterm protection (in the model assumed at $90 \%$ effectiveness for a duration of 20 years, as seen for other conjugate vaccines). In an aggregate analysis-each scenario in turn being compared with "doing-nothing"-all scenarios provided acceptable cost- effectiveness ratios per life-year gained (Table 2) if we recall that for the Netherlands once a threshold has been suggested at $€ 20,000$ per life-year gained (Hubben et al. 2007). This might be labelled "the aggregate approach", also sometimes referred to as calculating average cost-effectiveness. However, it was stressed during the decision-making process that the more accurate comparison would be the extra costs and extra health gains for one scenario over the other, rather than comparing with the "doing-nothing" alternative for all. Since strategies could easily be ranked according to the number of doses provided and thus the investment costs required, an important question arose, namely how many extra costs are entailed in relation to the extra health gains if providing one or two extra dose(s) as compared to giving one dose at 14 months? This might be labelled "the incremental approach" (Table 2, last two columns). The incremental approach is recommended or even prescribed in many international guidelines, including those in the Netherlands. Table 2 clearly indicates that
Table 2 Deaths averted (all and incremental) cost-effectiveness ratio (CER or ICER) in net costs per life year gained (in $2000 € \mathrm{~s}$ ) for three scenarios of meningococcal vaccination in the Netherlands

\begin{tabular}{lllll}
\hline & $\begin{array}{c}\text { Deaths } \\
\text { averted }\end{array}$ & CER & Incremental & ICER \\
\hline $\begin{array}{l}\text { Age of vaccination } \\
\text { 14 months }\end{array}$ & 20.5 & 2,200 & NA & $2,200^{*}$ \\
5 and 6 months & 22.1 & 11,200 & $1.6^{* *}$ & $101,600^{* *}$ \\
2, 3 and 4 months & 22.7 & 19,900 & $2.2^{* *}$ & $146,900^{* *}$ \\
\hline
\end{tabular}

*As compared to "do nothing";

**as compared to "14 months";

$\mathrm{NA}=$ not applicable

Source: Welte et al. 2004

incremental cost-effectiveness is substantially different from aggregate cost-effectiveness, and it can be seen that providing one extra dose as compared to the one-dose schedule would represent a cost of $€ 101,600$ per life-year gained. Providing even two extra doses over the one-dose schedule would be still more expensive at $€ 146,900$. These figures were influential in the Dutch final decision to implement a one-dose meningococcal $\mathrm{C}$ vaccination strategy (Welte et al. 2005).

\section{Pneumococcal vaccine}

Introduction of pneumococcal infant vaccination using the seven-valent vaccine $\left(\operatorname{Prevnar}^{\circledR}\right)$ has been formally analysed twice in recent years in the Netherlands. In 2001, cost-effectiveness was estimated as highly unfavourable at $€ 82,700$ per life-year gained (Bos et al. 2003). Pneumococcal vaccination was not introduced at that time. Recently, new data have been analysed, and updated estimates of cost-effectiveness have been provided. A striking decrease in the cost-effectiveness ratio as compared to the 2001 estimate has been published again in Vaccine (Hubben et al. 2007). In particular, base-case cost-effectiveness was estimated at $€ 15,600$ per life-year gained. With regard to modifications in the data as compared to the 2001 analysis, one element clearly appeared as being the most influential. In 2000-2005, new evidence became available in the US regarding "herd immunity" effects of pneumococcal infant vaccination, i.e. how large-scale infant vaccination decreases invasive pneumococcal infections in elderly (Whitney et al. 2003; Lexau et al. 2005). The evidence was considered so convincing that it was included as an indirect health benefit in the Dutch model. US rates were implemented in the previously developed (2001) Dutch model, using straightforward proportional calculus for the specific serotypes included in the vaccine. Table 3 summarises the model results. It can be seen that the majority of life-years gained are derived from averted deaths in the 
Table 3 Health outcomes averted for pneumococcal vaccination in the Netherlands on an annual basis, divided over those protected through vaccination (infants and children) and those not vaccinated (elderly protected through "herd immunity")

\begin{tabular}{lll}
\hline Cases & Vaccination & Herd immunity \\
\hline Meningitis & & \\
Bacteremia & 55 & 29 \\
Pneumonia & 103 & 205 \\
Otitis media & 1,795 & $\mathrm{NA}^{*}$ \\
Long-term sequelae & 52,407 & $\mathrm{NA}^{*}$ \\
Mortality & 44 & \\
Deaths & 16 & 62 \\
Life years & 385 & 868 \\
\hline
\end{tabular}

*NA=not assumed

Source: Hubben et al. 2007

elderly through indirect protection. With the 2001 estimate not yet including the herd-immunity effects, the difference between both estimates for cost-effectiveness of pneumococcal vaccination is readily explained (Hubben et al. 2007).

Finally, Fig. 1 summarises the results showing the costeffectiveness outcome for varying discount rates for costs and life-years gained (the base-case estimate provided above at $€ 15,600$ was evaluated at $4 \%$ for both costs and life years). Discounting is performed to correct for time preference and generally adjusts all future costs, savings, and health gains to lower corresponding present-day values. Cost-effectiveness of vaccines crucially depends on the exact discount rate applied (Drummond et al. 2007). Figure 1 illustrates that the exact rate for discounting is particularly crucial for life years. Discussion on the methodology for discounting exists for health gains, whereas for costs and savings widespread consensus was achieved many years ago (Brouwer et al. 2005; Gravelle et al. 2007). In the Netherlands, for instance, the discount rate for costs at $4 \%$ has been applied for almost a decade. However, for health gains the Dutch recently changed from $4 \%$ to $1.5 \%$, with an obvious major impact on the cost-effectiveness of vaccines (Foundation for Health Care Insurance 1999, 2004). As a result of the decrease in the discount rate for health effects, Fig. 1 illustrates that the cost-effectiveness ratio for pneumococcal vaccination decreases from $€ 15,600$ to just over $€ 10,000$ per life-year gained.

HPV vaccine

One of the HPV vaccines was evaluated for inclusion in the Dutch Drugs Reimbursement System based on its therapeutic and health-economics characteristics. Gardasil ${ }^{\circledR}$ was judged to have evident therapeutic added value; however, the health economics report provided by the manufacturer was initially considered insufficient in 2007 (www.vcz.nl, accessed 20 January 2008). The criticism was directed towards (1) the application of the per-protocol analysis from the clinical trial rather than the preferred intention-totreat analysis as the basis was used for economic analysis and (2) the inadequate underpinning of some of the major parameters in the health-economic model, in particular those related to QALYs and to indirect costs of production losses.

Cost-utility was estimated for two age groups: 1315 year olds and 16-26 year olds. Base-case cost utilities were estimated at $€ 21,900$ and $€ 29,900$ per QALY, respectively, assuming lifetime protection of the vaccine against serotypes $6,11,16$, and 18 . Also, it was shown that if the duration of protection was lowered to the 5 years for which evidence was available, cost utilities would in the meantime become unacceptably high (in the range of $€ 70,000-80,000$ for both age groups). Despite the fact that the analysis was performed accounting for the already lowered discount rate for QALYs at $1.5 \%$, results were still
Fig. 1 Incremental costeffectiveness ratio (ICER) of pneumococcal vaccination in net costs (in $2004 € \mathrm{~s}$ ) per life-year gained for varying discount rates for costs (and savings) and health effects (i.e. life years) Source: Hubben et al. 2007

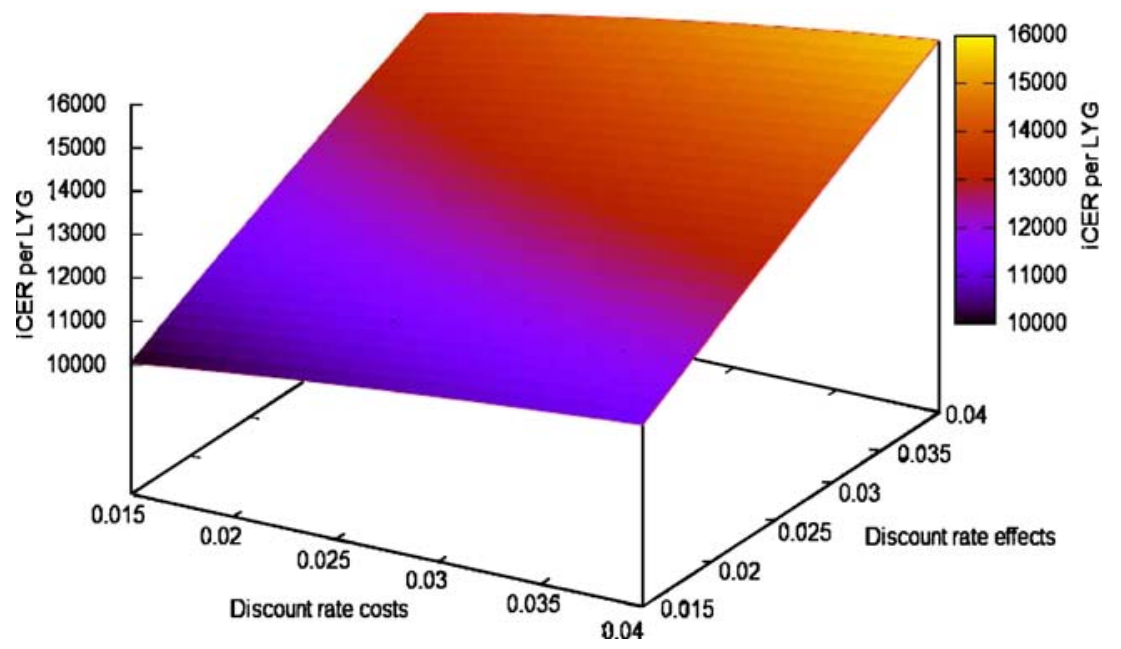


very sensitive for discounting such health gains. In particular, in the absence of discounting health gains at all (a rate of $0 \%$ ), base-case cost-utility ratios were consistently halved. It is noteworthy that (near) non-discounting of health gains is still advocated and motivated, in particular in the area of infectious diseases vaccines (Bos et al. 2004).

The prolonged decision on the reimbursement of the HPV vaccine within the Dutch Drugs Reimbursement System is unique in that it is currently the sole product having so far been denied for the Reimbursement System based on the health economics report. [Previously, ivabradine was denied reimbursement based on health-economics arguments. However, in a re-assessment positive advice on reimbursement has been provided, including a positive opinion on the health economics report (www.cvz.nl, accessed 20 January 2008)].

Also noteworthy is that the Dutch situation differs from that of many other countries where the HPV vaccine has immediately received a positive recommendation for reimbursement or has already been incorporated in reimbursement systems, either Drugs Reimbursement System-like or NIPlike environments. These countries include amongst others Belgium, Denmark and Greenland, France, Germany, Italy, Switzerland, and the UK. Such positive opinions have often been based on health economics as well. This illustrates that the Dutch health economics assessments may well differ from those in other countries regarding the immediate interpretation of added value of innovative therapeutic and prophylactic products, such as the HPV vaccine.

Since early April 2008, a formal positive recommendation to include the HPV vaccine in the Dutch NIP does exist. In particular, the Health Council advises to vaccinate 12-year-old girls and design a catch-up program (GR 2008). Based on assumed lifetime protection (if needed with a booster included at the age of 30 ), cost-utility is indicated to grossly vary from $€ 20,000$ to $€ 30,000$ per QALY, which is in line with the analyses that were previously done for the GVS for the young teenage girls. Additionally, it is stated that the design of the catch-up program should be guided by health-economic outcomes, which could imply that girls aged 16-18 would not be included given their risk of already being exposed to the virus. For those girls falling outside the catch-up, the Health Council advises the $\mathrm{MoH}$ to reconsider reimbursement within the Drugs Reimbursement System (GR 2008).

\section{Discussion and conclusions}

In the Netherlands, two routes exist for the reimbursement of vaccines; i.e. the Drugs Reimbursement System and the NIP. Some differences have been discussed going through the examples provided above. One further aspect regarding health-economic evidence should also be noted. In particular, economic analyses in the framework of reimbursement for the Drugs Reimbursement System are generally done by the producers themselves (or allied consultancy companies), whereas those for the NIP are required to be performed by independent research institutes, such as universities and public health bureaus. In-house analyses done by the companies have the advantage of speed; those done by independent institutes appear to require more time in practice. For short-term reimbursement-generally with yet limited use-the Drugs Reimbursement System seems therefore very suitable, whereas for universal large-scale use evaluation within the procedure for NIP seems more suitable.

We have described how the role of health economics has recently increased in importance in Dutch public health decision-making concerning vaccines. Health-economic assessments, as seen above, have been crucial for the reimbursement of vaccines against meningococcal $\mathrm{C}$, pneumococcal, and HPV infections. Such assessments are particularly crucial to the Foundation for Health Care Insurance and the Health Council when making their recommendations to the $\mathrm{MoH}$. The specific choice of vaccination strategy against meningococcus $\mathrm{C}$, the shift from deciding against implementing pneumococcal vaccination, and the prolonged decision on the reimbursement for the quadrivalent HPV vaccine can all be related to a health-economics component in the recommendation process. Currently, this HPV vaccine is the only product denied for the Dutch Drugs Reimbursement System based on the health-economics report.

This paper has outlined the application of guidelines for health-economics research in the practice of economic evaluation of vaccines. In particular, the usefulness of a rigid incremental approach in the analytic design has been considered for meningococcal $\mathrm{C}$ vaccination. Furthermore, relevance of the specific and adequate model choice has been shown for the seven-valent pneumococcal vaccine, where a model specification was chosen to enable inclusion of "herd immunity" effects. Both the examples of pneumococcal vaccine and the HPV vaccine illustrated the sensitivity to the discount rate for health gains if vaccines are evaluated. Discussions on the exact methodologies to be used for discounting are of great importance in this specific area of public health.

Finally, we have illustrated the Dutch interpretation of public health-economic analyses of new vaccines, which often varies widely from that in other countries. Three examples are of particular interest. The Dutch one-dose strategy for meningococcal vaccination was motivated by health-economic considerations and differs from the choice in other major countries. The seven-valent pneumococcal vaccine was introduced in the NIP years after many other countries had done so. And lastly, the Dutch reserved position towards introducing HPV vaccination, despite a 
promising health-economics potential, has resulted in a situation in which the vaccine is not yet reimbursed in the Netherlands, as opposed to many other countries. However, a formal positive recommendation of the Health Council became available early in 2008, and discussions on reimbursement have started again, including potential costeffectiveness and cost-utility within the NIP.

Acknowledgements My thanks go to G.A.A. Hubben for his helpful suggestions in the writing of this article.

Conflict of Interest Prof Maarten Postma has received grants from various manufacturers of vaccines to finance $\mathrm{PhD}$-research on costeffectiveness of vaccines.

Open Access This article is distributed under the terms of the Creative Commons Attribution Noncommercial License which permits any noncommercial use, distribution, and reproduction in any medium, provided the original author(s) and source are credited.

\section{References}

Bos JM, Rumke H, Welte R, Postma MJ (2003) Epidemiologic impact and cost-effectiveness of universal infant vaccination with a 7 valent conjugated pneumococcal vaccine in the Netherlands. Clin Ther 25:2614-2630

Bos JM, Beutels P, Annemans L, Postma MJ (2004) Valuing prevention through economic evaluation; some considerations regarding the choice of discount model for health effects with focus on infectious diseases. Pharmacoeconomics 22:1171-1179

Brouwer WBF, Niessen LW, Postma MJ et al (2005) Need for differential discounting of costs and health effects in cost effectiveness analysis. BMJ 331:446-448

Drummond MF, Chevat C, Lothgren M (2007) Do we fully understand the economic value of vaccines? Vaccine 25:5945-5957

Gravelle H, Brouwer W, Niessen L (2007) Discounting in economic evalutations: stepping forward to optimal decision rules. Health Economics 16:307-317

Foundation for Health Care Insurance (College voor Zorgverzekeringen; CvZ) (1999) Guidelines for pharmacoeconomic research. Amstelveen

Foundation for Health Care Insurance (College voor Zorgverzekeringen; CvZ) (2004) Updated guidelines for pharmacoeconomic research. Diemen

Health Council (GezondheidsRaad; GR) (2002) Universal Vaccination against Meningococci and Pneumococci (in Dutch). The Hague

Health Council (GezondheidsRaad; GR) (2004) Vaccination against Pertussis (in Dutch). The Hague: GR
Health Council (GezondheidsRaad; GR) (2005) Vaccination of Infants against Pneumococcal Infections (in Dutch). The Hague

Health Council (GezondheidsRaad; GR) (2007) The Future of the National Immunization Program; towards a program for all ages (in Dutch). The Hague

Health Council (GezondheidsRaad; GR) (2008) Vaccination against Cervical Cancer (in Dutch). The Hague

Heeg BMS, Buskens E, Knapp M et al (2005) Modelling the treated course of schizophrenia: Development of a discrete event simulation model. Pharmacoeconomics 23(S1):17-33

Heeg BMS, Peters RJG, Botteman M, van Hout A (2007) Long-term clopidogrel therapy in patients receiving percutaneous coronary intervention. Pharmacoeconomics 25:769-783

Hubben GAA, Bos JM, Glynn DM et al (2007) Enhanced decision support for policy makers using a web interface to healtheconomic models-Illustrated with a cost-effectiveness analysis of nation-wide vaccination with the 7-valent pneumococcal conjugate vaccine in the Netherlands. Vaccine 25:3669-3678

Lexau CA, Lynfield R, Danila R et al (2005) Changing epidemiology of invasive pneumococcal disease among older adults in the era of pediatric pneumococcal conjugate vaccine. JAMA 294:2043-2051

Postma MJ (2003) Pharmacoeconomic research. Pharmacy, World \& Science 25:245-246

Postma MJ, Jansema P, Scheijbeler HWKFH, van Genugten MLL (2005) Scenarios on costs and savings of influenza treatment and prevention for Dutch healthy working adults. Vaccine 23:5365-5371

Postma MJ, Nijman HW, Daemen CAHH et al (2007a) Costeffectiveness of Human Papilloma Virus (HPV) 16/18 Vaccines against Cervical Cancer in the Netherlands. Vaccine Vaccine Congress 9-11 Dec 2007; Abstract Book

Postma MJ, Novak A, Scheijbeler HWKFH, Gyldmark M, van Genugten MLL, Wilschut JC (2007b) Cost effectiveness of oseltamivir treatment for patients with influenza-like illness who are at increased risk for serious complications of influenza; illustration for the Netherlands. Pharmacoeconomics 25(6):497-509

Rutten F (2004) Health technology assessment and policy from the economic perspective. Int J Technol Assess Health Care 20:67-70

Stolk EA, Busschbach JJV, Caffa M et al (2000) Cost utility analysis of sildenafil compared with papaverine-phentolamine injections. BMJ 320:1165-1168

Thiry N, Lambert M-L, Cleemput I, Huybrechts M, Neyt M, Hulstaert F, De Laet Ch (2007) HPV Vaccinatie ter Preventie van Baarmoederhalskanker in België. Brussels: Federaal Kenniscentrum voor de Gezondheidszorg (KCE)

Welte R, van den Dobbelsteen G, Bos JM et al (2004) Economic evaluation of menigococcal serogroup $\mathrm{C}$ conjugate vaccination programmes in The Netherlands and its impact on decision making. Vaccine 23:470-479

Welte R, Trotter CL, Edmunds WJ et al (2005) The role of economic evaluation in vaccine decision making. Pharmacoeconomics 23:855-474

Whitney CG, Farley MM, Hadler J et al (2003) Decline in invasive pneumococcal disease after the introduction of proteinpolysaccharide vaccine. N Eng1 J Med 348:1737-1746 